\title{
THE SPLEEN AND BLOOD EOSINOPENIA
}

\author{
BY \\ SIMON SEVITT \\ From the M.R.C. Research Unit and Pathology Department, Birmingham \\ Accident Hospital
}

(RECEIVED FOR PUBLICATION MAY 29, 1954)

Within a few hours of injury or burning the number of eosinophils in the blood falls progressively to reach low or zero values and this eosinopenia (Fig. 1) lasts up to a few days (Laragh and Almy, 1948; Roche, Thorn, and Hills, 1950 ; Hardy, 1950 ; Sevitt, 1951, 1954 : Evans and Butterfield, 1951).

The endocrine control of eosinopenia is known to be due to release of adrenocortical hormones through stimulation of the anterior pituitary, but the manner in which the eosinopenia is produced is in doubt. The question has been recently reviewed by Essellier, Jeanneret, and Morandi (1954). Several possible explanations could account for the eosinopenia, viz., (1) inhibited release of

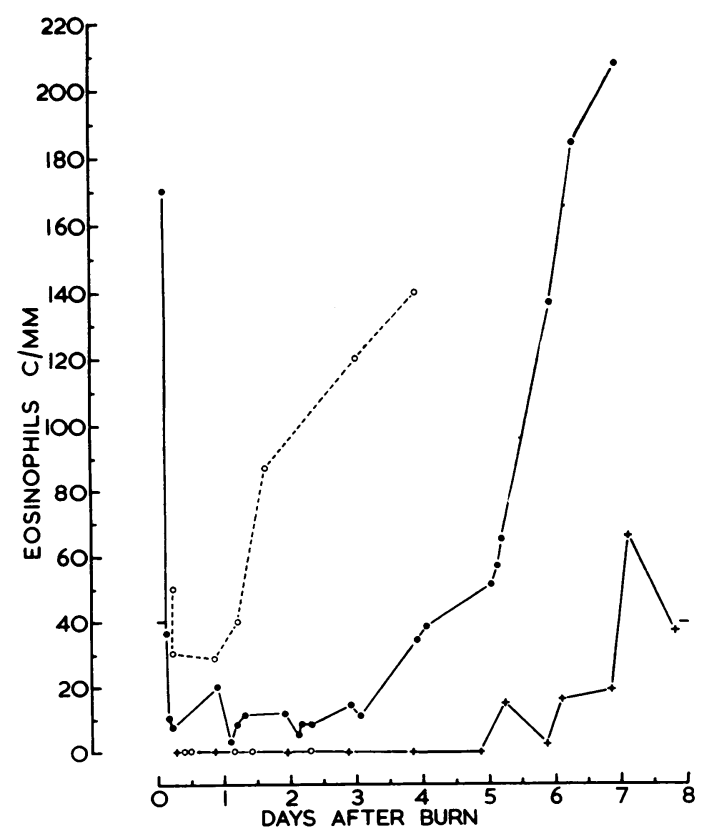

FIG. 1.-Changes in the blood eosinophil count in three burned patients. In one patient the falling of the count soon after burning is seen and this is followed by a period of eosinopenia which is present in all three. The eosinopenia lasted one, five, and seven days respectively and was followed by a rise in the count. eosinophil leucocytes from the bone marrow, (2) destruction of eosinophils in the blood, (3) redis- tribution of the eosinophils in the tissues, and (4) $\stackrel{\vec{N}}{\mathrm{~N}}$ redistribution followed by destruction in the tissues.응

In this paper the role played by the spleen in? redistribution and destruction will be considered. $\vec{T}$

\section{Eosinophils in the Normal Spleen}

The abundance of eosinophils in the spleens of previously healthy subjects dying within a few $\overrightarrow{0}$ hours of trauma or other catastrophe and of those splenectomized within a similar period indicates that the normal spleen contains many eosino-o phils (Sevitt, 1955). Similar numbers of eosinophils in the spleens of patients with Addi-O음 son's disease indicate that splenic eosinophilia is not due to a rapid post-traumatic filtration from $\cong$ the blood under the influence of adrenocorticali $\overrightarrow{\overrightarrow{0}}$ hormones. The densities of the eosinophils in 3 $5 \mu$ histological sections usually range from 200 to 700 per 100 high-power fields or from 6,000 . to 25,000 per c.mm. of tissue. This is many timesos the normal concentration in the blood, and sincethe normal spleen is not eosinopoietic (Biggart 3 . 1932) the spleen must normally filter eosinophilso from the blood.

\section{Splenic Eosinophils after Burning and Trauma}

It was also found that within 12 to 24 hourso of severe injury or burning the number of eosino phils in the spleen becomes reduced until eosinos penic values of fewer than 50 eosinophils per $100 \mathrm{~N}$ high-power fields are reached (Fig. 2). Indeed nearly every patient dying one to several days aftero injury or burning died with an eosinopenic spleen.

In a number of patients dying between 12 and 24 hours after injury or burning, splenic eosino philia was found. At this time, however, the blood eosinopenia would have been well estab $\mathcal{O}^{-}$ lished. This fact suggests that eosinopenia of the blood precedes eosinopenia of the spleen. Furthe $\frac{?}{0}$ evidence of this hypothesis was found by following the blood eosinophil counts after injury in three 
FIG. 2.-Splenic eosinophil counts (per 100 high-power fields) in three groups of patients, fatally burned, fatally injured, and splenectomized. These are related to the intervals between injury and death or splenectomy. During the first 24 hours many of the spleens contain many eosinophils varying from 100 to 658 per 100 high-power fields. After this nearly all the spleens contain relatively few eosinophils, particularly in the patients dying from burns. These results indicate that splenic eosinopenia occurs within 12 to 24 hours of injury or burning and continues (or is renewed) during the next few days.

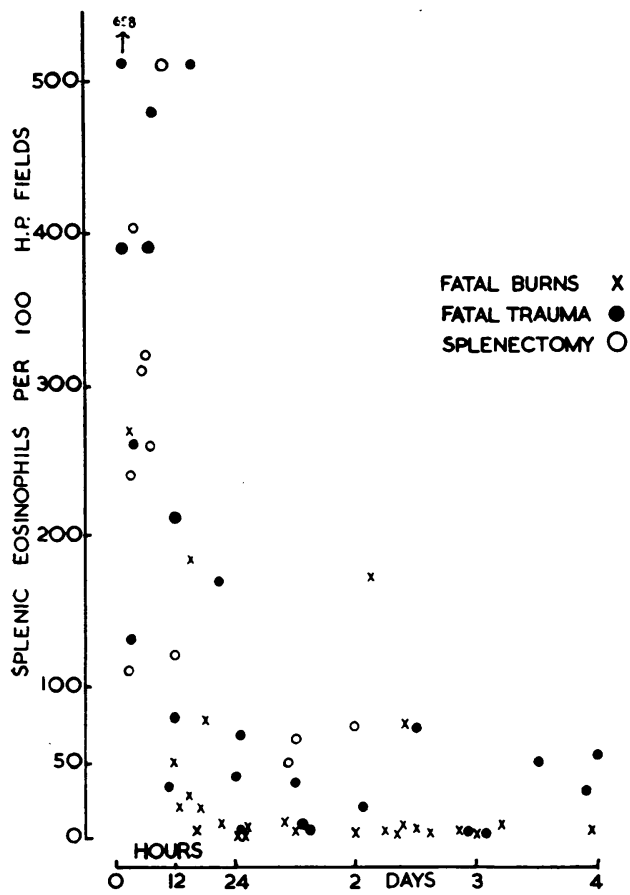

NTERVAL BETWEEN NUURY ANO DEATH OR SPLENECTOMY.

patients later undergoing splenectomy for traumatic rupture of the spleen, and then estimating the densities of the eosinophils in the spleens.

The blood eosinophil counts two, two and a half, and 13 hours after injury were only 6,3 , and 1 per c.mm. (Fig. 3), whereas the spleens removed one, four, and two hours later contained considerable numbers of eosinophils $(238,322$, and 507 per 100 high-power fields). That these spleens would have become eosinopenic some hours later had they not been removed is shown by relating the eosinophil values in 11 surgically removed ruptured spleens (including the spleens of these three patients) to the intervals between the accident and splenectomies. The five spleens removed within three to seven hours of injury were eosinophilic (110 to 403 eosinophils per 100 high-power fields), the spleens removed 12 and 13 hours after injury also had densities of 118 and 507 eosinophils, while lower values of 50,64 , and 74 respectively were found in the organs removed 36 , 36 , and 48 hours after injury.
These findings are consistent with two hypotheses. First, the spleen removes eosinophils from the circulation and destroys them. Secondly, a non-splenic mechanism which produces blood eosinopenia also produces eosinopenia of the spleen through the discharge of splenic eosinophils into the blood stream.

\section{Necrotic and Degenerate Eosinophils in the Spleen after Injury and Burning}

Necrotic eosinophils had ill-defined karyolytic nuclei or were cells without nuclei. In the latter only the bright red granules were enclosed in a cytoplasmic membrane, and sometimes when the membrane was ruptured the eosinophils appeared merely as an irregular clump of free granules. These eosinophils were not included when estimating the eosinophil leucocyte densities. Other changes affected the granules, which were sometimes swollen and appeared to coalesce or were reduced in density.

More necrotic eosinophils were found in spleens containing many normal eosinophils than in those containing few of these cells. The former usually contained 20 to 70 necrotic cells per 100 high-power fields ; for example, the spleen of a man dying three hours after burning had 37 necrotic eosinophils and 273 normal eosinophils per 100 high-power fields. On the other hand, the density of necrotic eosinophils in the eosinopenic spleens was small, varying usually from 1 to 8 per

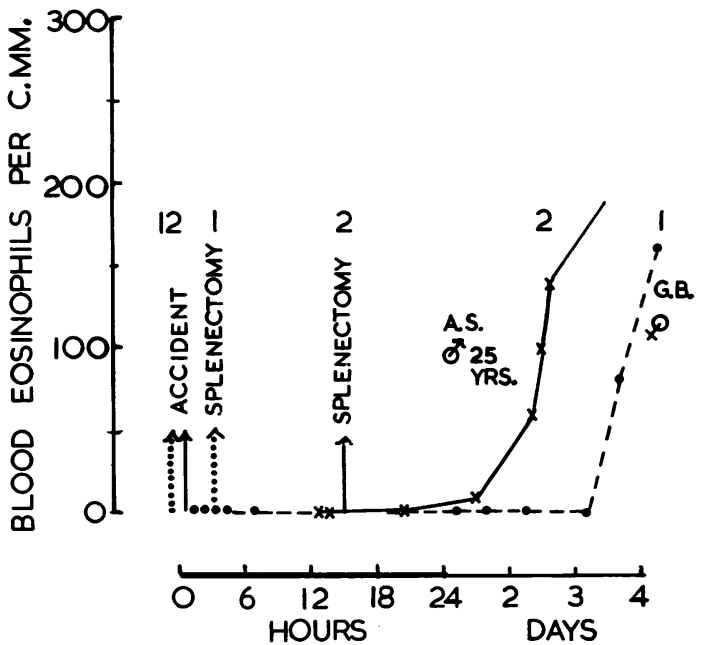

FIG. 3.- Serial blood eosinophil counts in two patients (1 and 2) before and after splenectomy for traumatic rupture of the spleen. Blood eosinopenia was established before operation and continued after splenectomy for about two and $a$ half and one and tinued after splenectomy for about two and a half and one and eosinophils per 100 high-power fields), indicating that blood eosinophils per 100 high-power fields), indicatin
eosinopenia occurs before splenic eosinopenia. 
100 high-power fields ; for example, the spleen of a patient dying three days after severe burning had 1 necrotic and 2 normal eosinophils per 100 high-power fields.

The presence of these necrotic and degenerate cells suggests that the spleen either destroys viable eosinophils or removes degenerate eosinophils from the circulation.

\section{Eosinopenia in Patients Splenectomized after Trauma}

Eight previously healthy males, including four whose spleens were sectioned, varying in age from 14 to 61 years, were studied. Each had received injuries to the thorax and/or abdomen resulting in a rupture of the spleen. The patients were transfused with blood. The spleens of six were removed under general anaesthesia three to seven hours after injury, in the seventh at $\mathbf{1 3}$ hours, and in the eighth operation was delayed until 48 hours because of difficulty in diagnosis.

Spontaneous Eosinopenia.-Blood eosinophil counts, two to four times a day for three to five days, were carried out on seven patients. In four, the counts were started three to 12 hours after splenectomy, and in the three others one, two, and four hours before operation. A profound eosinopenia was found in each patient with very low or zero eosinophil counts, and this lasted one and a half to two and a half days (Fig. 3). The eosinopenia was ended by a sudden and progressive rise in the count. In five patients the blood eosinophil counts returned to normal values in two or three days; in the other two temporary eosinophilic values were found (maximum counts 1,200 and 788 per c.mm.).

Similar degrees and periods of eosinopenia are found after severe trauma and major abdominal operations (Laragh and Almy, 1948 ; Roche et al., 1950 ; Hardy, Richardson, and Dohan, 1953 ; Sevitt, unpublished observations). The absence of the spleen, therefore, did not appear to influence the degree of duration of the eosinopenia due to post-traumatic adrenocortical activity. Such activity is intense and probably maximal, and the absence of the spleen may have been compensated for by other mechanisms. The spleen's role in the production of eosinopenia might be disclosed by submaximal stimulation of the adrenal by A.C.T.H.

Induction of Eosinopenia by A.C.T.H.-Among the effects of A.C.T.H. through its stimulation of the adrenal cortex is a considerable reduction in the blood eosinophil count, and this eosinopenic property has been used as a method of evaluating adrenocortical function (Thorn, Prunty, and Forsham, 1947 ; Dougherty and White, 1947 ; Hills, Forsham, and Finch, 1948 ; Forsham, Thorn, Prunty, and Hills, 1948 ; Sevitt, 1954). Injecting 20 to $25 \mathrm{mg}$. of A.C.T.H. lowers the eosinophil count usually within an hour of injection. and always within two hours (Hills et al., 1948 ; Sevitt, 1954); the maximum fall (Fig. 4) in the count occurs three to five hours, usually four hours, after injection and nearly always ranges between $60 \%$ and $90 \%$ of the pre-injection count (mean value $70 \%-75 \%$ ).

Seven of the splenectomized patients were tested with A.C.T.H. when the spontaneous blood eosinopenia had ended and either during or shortly after the post-eosinopenic rise of the eosinophil count. The patients were well and there was no evidence of pituitary or adrenocortical dysfunction. Therefore, any abnormality in the response of the
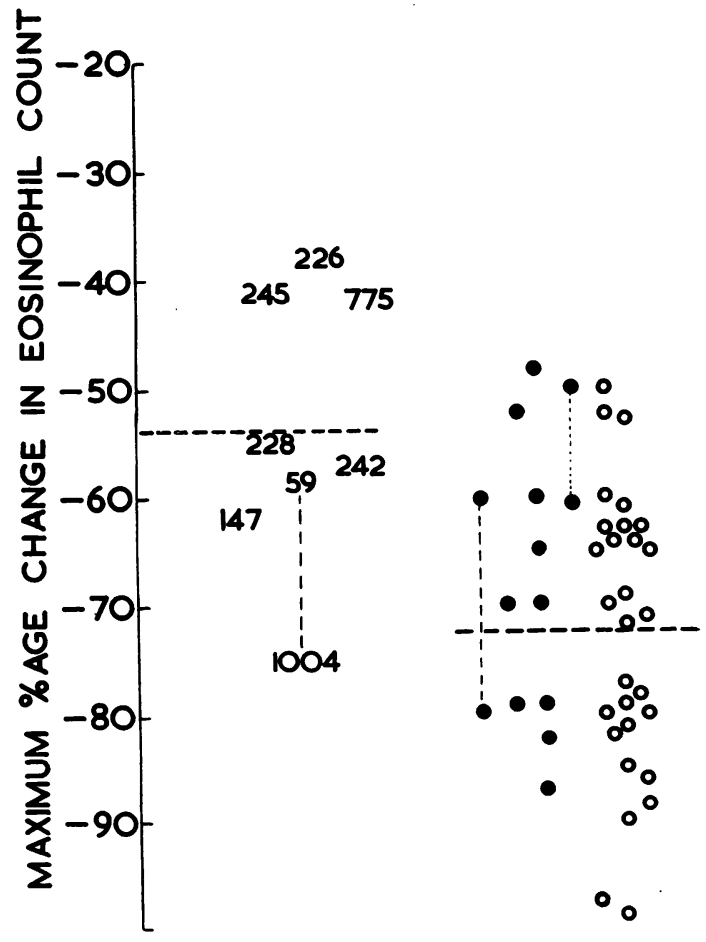

FIG. 4-A.C.T.H. tests in recently splenectomized patients. Each point is the result of one test and is represented by a numeral which is the pre-injection value of the blood eosinophil count per c.mm. Its vertical position expresses the maximum percentage lowering of the count. To compare with these are the results of lowering of the in burned and other patients. The horizontal A.C.T.H. tests in burned and other patients. The horizontal interrupted lines are the mean values in the two groups. The vertical lines join the results of tests on one pafient. Three of the tests on the splenectomized subjects were definitely abnormai and the values are significantly less than the values obtained in the burned patients (see text). Burned patients. O Other patients. 
blood eosinophils to the injection of A.C.T.H. would be evidence, not of adrenocortical dysfunction but of the role which the spleen plays in the production of blood eosinopenia.

\section{Methods}

The A.C.T.H. (batches J16205, J27511, and J28112) used was previously found to produce the expected eosinopenia in normal and burned persons. One intramuscular injection of $20 \mathrm{mg}$. freshly dissolved in about $2 \mathrm{ml}$. of distilled water or saline was given between 11 a.m. and 1 p.m.

Blood eosinophil counts on capillary blood were made by the direct "wet field" method of Dunger (1910) using a modified eosin-acetone water diluent. The blood was diluted to 1 in 20 in each of two pipettes and the number of eosinophils in four FuchsRosenthal fields, corresponding to $0.65 \mathrm{c} . \mathrm{mm}$. of blood, were counted.

Counts were made 15 to 60 minutes before the injection, at the time of injection, and hourly thereafter for four to six hours. The eosinophil counts were plotted, the shape of the curve was examined, and the maximum fall of the count was expressed as a percentage of the pre-injection count.

\section{Results}

Eight A.C.T.H. tests were carried out on seven patients. Tests on six patients were made on the third, sixth, sixth, seventh, eleventh, and thirteenth days after splenectomy, and on the fourth and eleventh days in the seventh patient.

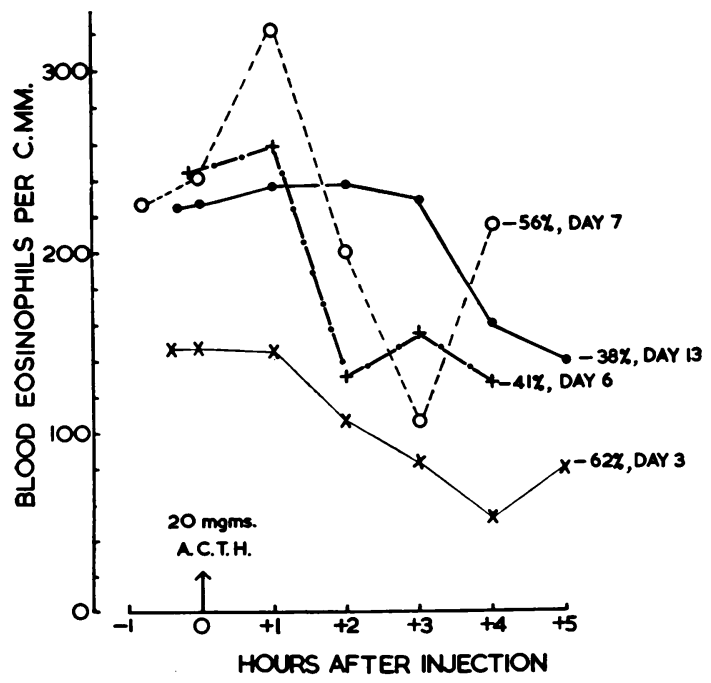

FIG. 5.-Blood eosinophil responses following injection of $20 \mathrm{mg}$. of A.C.T.H. to recently splenectomized patients. Only one of the four curves $(X-X)$ is normal. In one patient the count rises considerably at one hour after injection and then falls; in another there is an abnormal delay of three hours before the count falls; in two patients the counts fall by only $38 \%$ and $41 \%$ count falls; in two patients
of the pre-injection values.
Eosinopenia was induced in each patient, but the results from only two subjects fulfilled the minimum criteria of normality. In two patients (three tests) the counts did not fall for the first two or three hours after injection; indeed, increases of $5 \%$ to $20 \%$ over the pre-injection levels developed. In two others the counts increased by $5 \%$ and $33 \%$ respectively at one hour after injection but at two hours had fallen. This pre-eosinopenic increase of the eosinophils lasting one to three hours is not seen in normal persons or in burned patients.

Although the lowest eosinophil counts occurred at the normal time, three to five hours after injection of A.C.T.H., often they were less than normal. In three patients the counts fell by only $38 \%, 41 \%$, and $43 \%$ of the pre-injection levels, in the other four subjects (five tests) the counts fell by $55 \%, 57 \%, 62 \%, 59 \%$, and $75 \%$. The mean percentage decrease in the eight tests was $53 \%$ compared to a mean fall of $70 \%$ to $75 \%$ in normal persons and $67 \%$ in burned patients (Fig. 4). Statistical analysis by the $t$ test showed a significant difference between the results in the splenectomized and burned patients $(p<0.05)$.

\section{Discussion}

Eosinopenia can be induced in splenectomized rats and mice by adrenaline and A.C.T.H. (Speirs and Meyer, 1949 ; McDermott, Fry, Brobeck, and Long, 1950) so that the spleen is not essential for eosinopenia in these animals, but whether it plays some part in the intact animal is in dispute. Spain and Thalhimer (1951) claimed that eosinophils temporarily accumulate in the spleens of mice after cortisone, but no histological increase was observed by Mach, Brügger, Della Santa, and Fabre (1950). Moreover, Solomon and Humphreys (1951) found that during the development of blood eosinopenia in dogs the splenic veins often contained more eosinophils than the femoral arteries. This would indicate that the spleen discharged eosinophils into the circulation while eosinopenia of the blood is taking place.

It has now been found that blood eosinopenia lasting one and a half to two and a half days occurs or continues spontaneously after splenectomy. Soon after this it can be induced by A.C.T.H. Therefore the spleen is not essential for eosinopenia in man.

A similar conclusion was reached by Essellier, Morandi, and Stein, who found that a similar type of eosinopenia was induced by A.C.T.H. in both normal and splenectomized subjects. However, 
this has not been the present experience. The eosinopenia induced by A.C.T.H. may be preceded by a temporary increase in the eosinophil count and/or prolonged delay of one to three hours before the count falls. This indicates that after A.C.T.H. eosinophils are mobilized into the blood from other body tissues, and suggests that this early mobilization is normally masked by the spleen. The degree of eosinopenia induced by A.C.T.H., often less than is normal, also suggests that the spleen plays a part in the mechanism of blood eosinopenia. The persistence of splenic eosinophilia for 12 to 24 hours after trauma when blood eosinopenia has already occurred, and the presence of necrotic eosinophils in most spleens, also suggests that the spleen filters eosinophils from the blood and destroys them. Essellier and Wagner (1952) found that blocking the reticulo-endothelial system in guinea-pig by tryptan blue prevented the induction of eosinopenia by A.C.T.H. If this were true for man, splenectomy would be expected to produce a variable effect upon the rate and degree of eosinopenia induced by A.C.T.H., depending upon the proportion of the reticuloendothelial system contained in a particular spleen. Such a variability, which occurred in the splenectomized patients after A.C.T.H., supports the belief that the reticulo-endothelial system, including the spleen, is responsible for the removal and destruction of the eosinophils from the blood.

The role of the spleen may be a minor one in some patients and hidden by other mechanisms: in other subjects it is more important, but the spleen is not essential for the production of blood eosinopenia.

\section{Summary}

The spleen is not essential for the production of blood eosinopenia in man, since this occurs spontaneously after splenectomy and can be induced by A.C.T.H. in recently splenectomized patients. However, the eosinopenia induced is frequently less than occurs in normal subjects and may be preceded by an abnormal delay before the eosinophil count falls, during which period it may rise. Moreover, the blood eosinopenia after injury precedes eosinopenia of the spleen and this organ contains necrotic as well as normal eosinophils. It is therefore suggested that the spleen plays some part in the removal and destruction of the eosinophils from the blood and in the production of eosinopenia.

I am grateful to my surgical colleagues, particularly Mr. R. Clarke and Mr. J. S. Horn, for their helpful co-operation. My thanks are also due to Miss A. J. Fisher, B.Sc., for statistical help, to $\mathrm{Mr}$. C. Richardson, of the Photographic Department of the Accident Hospital, and to my secretary. Miss M. Hayes.

The work was carried out in my capacity as a parttime member of the scientific staff of the Medical Research Council.

The A.C.T.H. was obtained through the courtesy of the Allocations Committee of the Medical Research Council and was prepared by Armour Laboratories.

\section{REFERENCES}

Biggart, J. H. (1932). J. Path. Bact., 35, 799.

Dougherty, T. F., and White, A. (1947). J. Lab. clin. Med., 32, 584. Dunger, R. (1910). Münch. med. Wschr., 57, 1942.

Essellier, A. F., Jeanneret, R. L., and Morandi, L. (1954). Blood, 9. 531 .

Morandi, L., and Stein, R. Unpublished data quoted by Essellier, A. F., Jeanneret, R. L., and Morandi, L. (1954).

and Wagner, K. F. (1952). Acta haemat., Basel, 8, 63.

Evans, E. I., and Butterfield, W. J. H. (1951). Ann. Surg., 134, 588.

Forsham, P. H., Thorn, G. W., Prunty, F. T. G., and Hills, A. G. (1948). J., clin. Endocr., 8, 15.

Hardy, J. D. (1950). Ann. Surg., 132, 189.

- Richardson, E. M., and Dohan, F. C. (1953). Surg. Gynec. Obstet., 96, 448.

Hills, A. G., Forsham, P. H., and Finch, C. A. (1948). Blood, 3, 755.

Laragh, J. H., and Almy, T. P. (1948). Proc. Soc. exp. Biol., N.Y. $69,499$.

McDermott, W. V., Fry, E. G., Brobeck, J. R., and Long, C. N. H. (1950). Yale J. Biol. Med., 23, 52.

Mach, R. S., Brügger, Y., Della Santa, R., and Fabre, J. (1950). Schweiz. med. Wschr., 80, 5.

Roche, M., Thorn, G. W., and Hills, A. G. (1950). New Engl. Med., 242, 307.

Sevitt, S. (1951). Brit. med. J., 1, 976. (1954). Ibid., 1, 541.

(1955). J. Path. Bact., in the press.

Solomon, D. H., and Humphreys, S. R. (1951). Blood, 6, 824

Spain, D. M., and Thalhimer, W. (1951). Proc. Soc. exp. Biol., N.Y. $76,320$.

Speirs, R. S., and Meyer, R. K. (1949). Endocrinology, 45, 403.

Thorn, G. W., Prunty, F. T. G.., and Forsham, P. H. (1947). Trans. Ass. Amer. Phvs., 60. 143. 